\title{
Research Efforts of GIFT, A Graduate Institute in All that is Steel: with an Example of Recent Achievement on Light-Weight Steel Development
}

\author{
Hae-Geon LEE \\ Vice President for Academic Affairs, Adama Science and Technology University (ASTU), Adama, Ethiopia. Now Professor \\ Emeritus, Graduate Institute of Ferrous Technology (GIFT), Pohang University of Science and Technology (POSTECH), Pohang, \\ 37673 Korea.
}

(Based on Honorary Member Lecture; held at Tokyo University of Science on March 23, 2016. Manuscript received August 9, 2016)

\begin{abstract}
The Graduate Institute of Ferrous Technology (GIFT) under the umbrella of Pohang University of Science and Technology (POSTECH) in Korea was established in 2005, aiming at education and research in all that is steel. It is currently run with three centers which have eleven laboratories in all, each of which focuses on a particular aspect of ferrous technology. GIFT offers both master's and PhD programs, both specialized in ferrous technology. It covers process, product and application of steels and steel-related materials. It also keeps developing close links with steel producers, users and supporters. The interaction happens via many mechanisms including collaborative projects, workshops, participation in teaching, employment of highly trained graduates, secondments from industry to conduct research at GIFT, etc. Such interactions are considered vital in the two-way transfer of knowledge, ideas and direction. In this report, the educational performance of GIFT is briefly summarized. The research emphasis of each center and focal research areas of each laboratory are also outlined. An example out of recent research outcomes of GIFT, which is about a novel approach to the development of light-weight steels, is elaborated in some detail.
\end{abstract}

KEY WORDS: higher education; graduate school; development of human resources; industry-academia collaboration; light weight steel.

\section{Introduction}

Steel is frequently the "gold standard" against which emerging structural materials are compared. What is often not realized is that this is a moving standard, with notoriously regular and exiting discoveries being made in the context of iron and its alloys. ${ }^{1)}$

It is nevertheless recognized that scholarship in ferrous materials has declined drastically in many parts of the academic world.

It was with this in mind that in 1995 the Pohang University and Science and Technology (POSTECH) initiated a proactive program, The Graduate School of Iron and Steel Technology (GSIST), in which graduate students were inspired in a deeper understanding of ferrous metallurgy through appropriate teaching and research. This was the program which led to the foundation, in September 2005, of the Graduate Institute of Ferrous Technology (GIFT), a further prodigious expansion of the original goals outlined in 1995.

GIFT has a simple mission: to become a forefront leader in all aspects of steel metallurgy and to act as a rich source of highly trained young scientists and technologists, not

* Corresponding author: E-mail: haegeon@astu.edu.et

DOI: http://dx.doi.org/10.2355/isijinternational.ISIJINT-2016-493 only to feed demands of the steel producing and using industries, but also to nurture creativity in this most fascinating of materials.

The Institute benefits from its close proximity to some of the major steel producers in Korea, including POSCO which has generously funded GIFT.

It is worth emphasizing at the outset that GIFT had an international perspective, with both staff and students welcomed from other parts of the world. The working language of all staff and students is English.

Since its inauguration as GIFT in 2005, it has successfully nurtured elite workforce in ferrous technology and produced research outcomes that are of use for now and for the near future. This article provides a succinct summary of GIFT in regard to its structure, activities and endeavors on education and research, and some achievements worth sharing with those who are keen in ferrous metallurgy.

\section{Vision, Mission and Strategies}

GIFT started its work with the vision of becoming a prominent center for steel education and research. Its mission encompassed to nurture global leaders specialized in steels who take roles responsible for the future of steel, to create innovative technologies in steels, and to establish the 


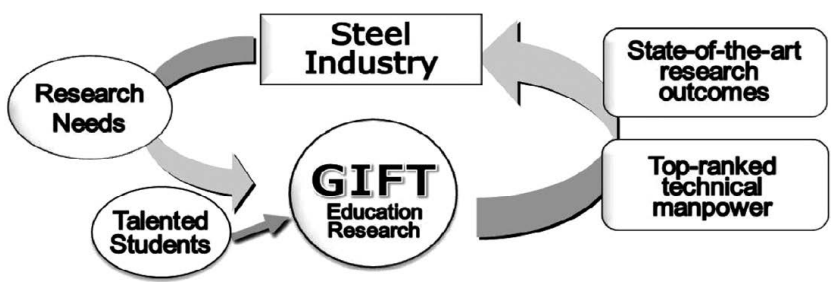

Fig. 1. Schematic diagram which shows the role of GIFT.

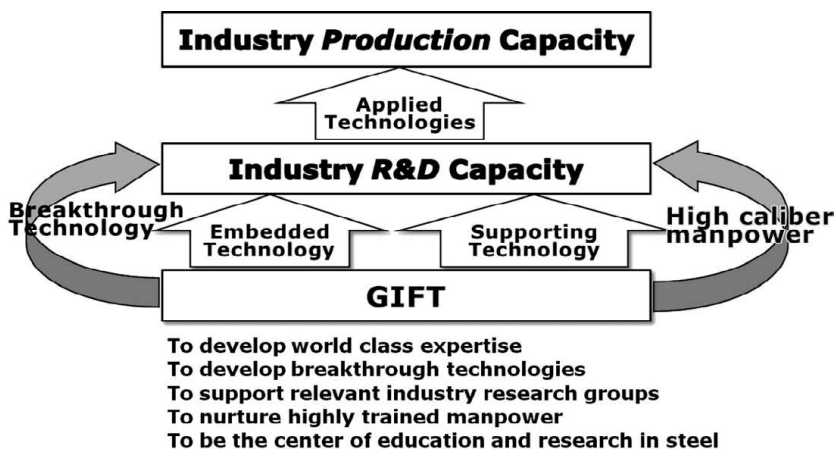

Fig. 2. Functions and roles of GIFT in relation to the steel-related industry.

global network of education and research in steels. The mission may be summarized as depicted in Fig. 1.

Fully realizing that education and research in steel are to be closely related to steel-related industry, GIFT started its activities by defining its position as to how to provide technological support in ferrous technology to the steelrelated industry. As can be seen in Fig. 2, GIFT provides the industry with the essential core components for enhancement of the industry R\&D capacity. These components include development of breakthrough technologies as well as embedded and supporting technologies. The industry R\&D function then adapts the so-developed technologies to be applicable to the production processes. In order to fulfill the mission, GIFT continues to develop world-class expertise and the top-of-the-range technologies, and nurture highly educated and trained manpower.

The first and foremost challenging task to establish a structure to enable GIFT workable for its planned mission was to invite the academic staff internationally who were preeminent in and firmly dedicated to steel for both teaching and research. It was the vital ingredient to provide a highly generous support and environment on research, educational and living conditions.

The other task was to recruit junior academic staffs who were well-educated in ferrous technology and had a strong passion in steel. They are to lead in the long run education and research in important areas of ferrous technology.

In addition to these it was planned to appoint a number of adjunct professors from all over the world, who would help in the development of GIFT and add to its ambitions.

\section{Structure and Its Evolvement}

There was a systematic plan to implement a number of research areas, each focusing on a particular aspect of ferrous technology, and each staffed by a leading professor, multiple numbers of junior academic staff, research associates and technicians. Figure 3 shows the initial plan on

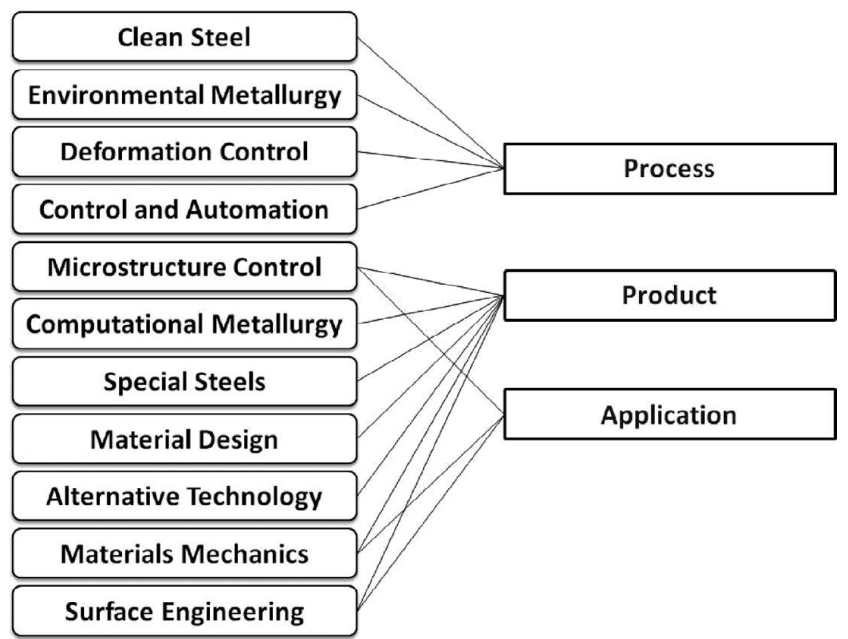

Fig. 3. Initial plan for research structure (laboratories).

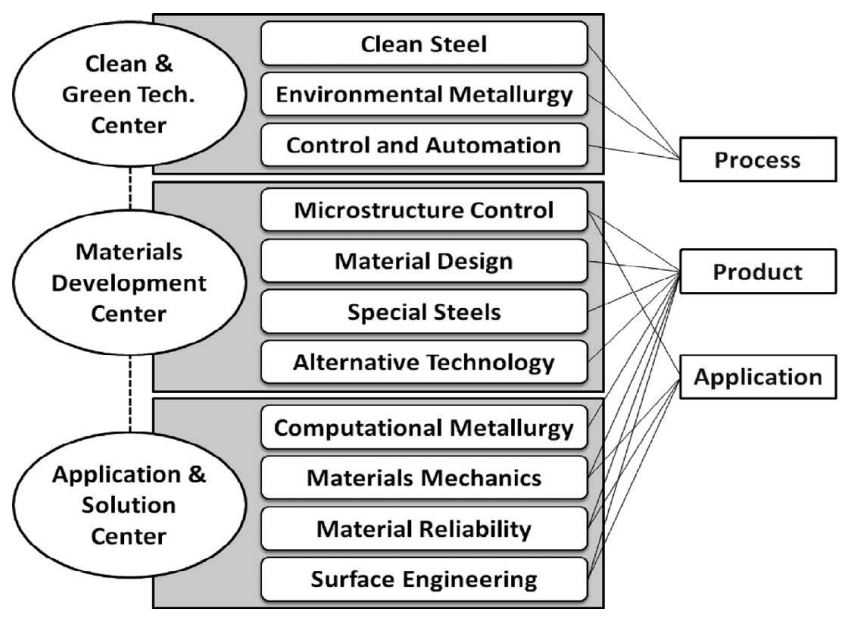

Fig. 4. Current research structure (laboratories).

establishment of research programs (laboratories):

The above structure of GIFT has been further evolved by adopting the center system as shown in Fig. 4, primarily to enhance cross-collaboration and cross-fertilization between inter-related technological areas.

\section{Education}

Since the aim is excellence in scholarship, graduate students are recruited on the basis of academic merit, enthusiasm for ferrous technology, and English proficiency as the working language at GIFT is English. Once admitted, they are fully funded and accommodated, irrespective of their country of origin. Recruits are from fields as diverse as metallurgy, materials science and engineering, physics, chemistry, mathematics, chemical engineering, electrical engineering, and mechanical engineering.

A master's program covers two years, with course work and a major research activity leading to the submission of a thesis for examination. A PhD program of three to four years duration involves a course work, but the major focus is undoubtedly research at the highest level.

The courses are all given by GIFT staff and designed to teach the most up-to-date science, but at the same time to inspire students to develop technologies which can benefit 
society as a whole.

The teaching program is unique in that it can be tailored to the needs of each individual student - the majority of courses are elective, with a few core requirements that every student must attain. There is considerable academic freedom to choose courses given in other parts of POSTECH. The main objective is to improve the career potentials of its graduates within the iron and steel related industries, whether this is in research or otherwise. The program is truly interdisciplinary in spirit and content. The statistics of the number of students enrolled each year is shown in Table $\mathbf{1 .}$

The foreign students have been from a number of different countries including China, Viet Nam, Iran, India, Turkey, Thailand, Indonesia and Zimbabwe.

The graduates who completed the master's degree have found a number of different jobs, but more than half of them have joined the $\mathrm{PhD}$ programs, either at GIFT or at some other places. Those who completed their PhD degree have found their job mostly at steel or steel-related industries. Figure 5 shows the job distribution of the graduates of both master's and doctoral degrees conferred by GIFT.

\section{Research}

As aforementioned, the Graduate Institute of Ferrous Technology (GIFT) is comprised of three centers which include eleven Laboratories in all, each of which focuses on a particular aspect of ferrous technology. GIFT is accommodated in its dedicated building of the total floor space of $24000 \mathrm{~m}^{2}$ (see Fig. 6).

Table 1. The number of students of GIFT (MSc $+\mathrm{PhD})$.

\begin{tabular}{ccccccccccccc}
\hline Year & 2005 & 2006 & 2007 & 2008 & 2009 & 2010 & 2011 & 2012 & 2013 & 2014 & 2015 \\
\hline Total & 9 & 31 & 46 & 73 & 99 & 106 & 116 & 117 & 105 & 96 & 95 \\
\hline Foreign & 6 & 10 & 12 & 16 & 14 & 9 & 10 & 15 & 12 & 8 & 8 \\
$\%$ & 66.7 & 32.3 & 26.0 & 21.9 & 14.1 & 8.5 & 8.6 & 12.8 & 11.4 & 8.3 & 8.4 \\
\hline
\end{tabular}

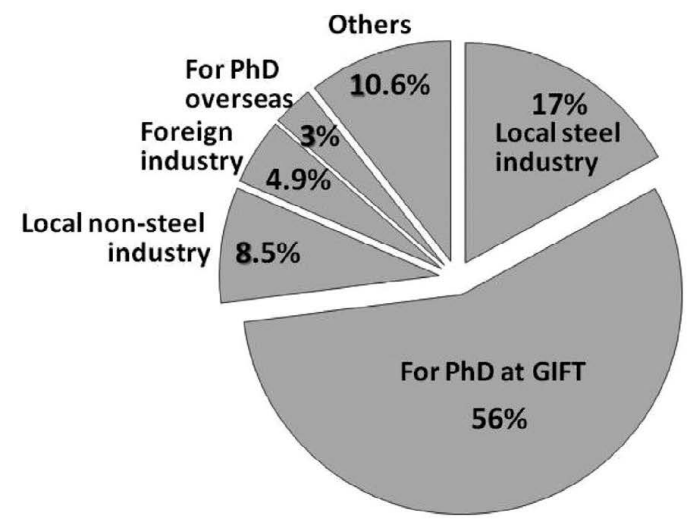

(a) Master's degree holders

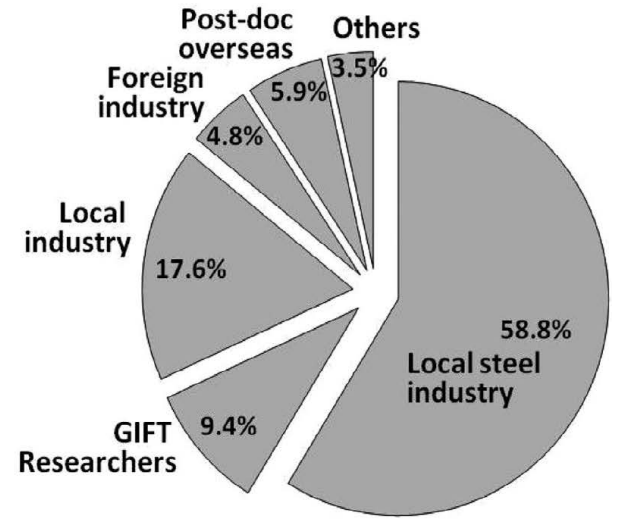

(b) PhD degree holders

Fig. 5. Job distribution of the graduates after completing the master's and PhD degrees. (a) Master's degree holders (b) PhD degree holders.

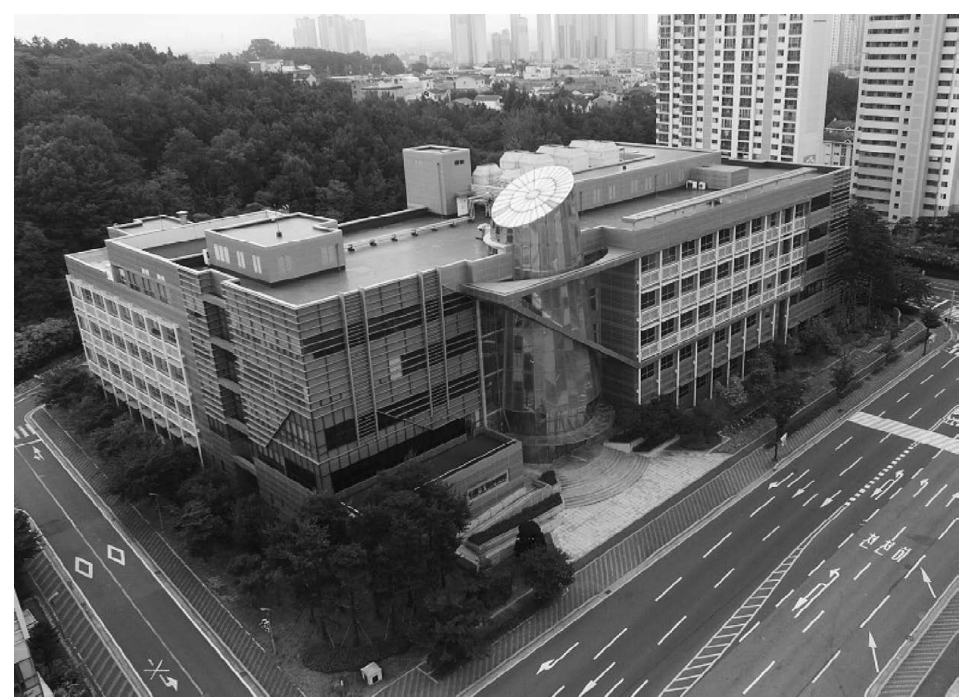

Fig. 6. The GIFT building. 
The nature and focal areas of the Centers and Laboratories of GIFT are briefly summarized in the following:

\subsection{Clean \& Green Technology Center}

The Clean \& Green Technology Center focuses on two key issues related in iron and steel: quality and environment. Research direction of the Center is therefore in line with quality improvement and environmental protection. The goals set by the Center are,

- To develop future-oriented technologies for clean steel-making, refining and casting

- To develop innovative iron-making processes using low grade ores and coals with less pollution materials and $\mathrm{CO}_{2}$ emission

- To develop leading edge process control and automation technologies for low cost and high productivity

The major focal points of research of the Center include;

- High temperature thermochemistry

- Physicochemical properties/reaction kinetics

- Heat and fluid flow dynamics

- Coal and coke technology

- Advanced agglomerate manufacturing technology

- $\mathrm{CO}_{2}$ sequestration technology

- Steel process control and automation

The Center is run with three research labs:

- Environmental Metallurgy Lab (EML) led by Prof. Sung-Mo Jung

- Clean Steel Lab (CSL) led by Prof. Youn-Bae Kang

- Control and Automation Lab (CAL) led by Prof. Sang Chul Won

A brief description on research emphasis of each of the labs is given below:

\subsubsection{Environmental Metallurgy Lab (EML)}

The Lab focuses on the in-depth understanding of the phenomena in ironmaking processes to meet the demand of environmental issues (resources, energy and $\mathrm{CO}_{2}$ issues), and apply them to industrial applications. The most important key words being spoken in the steel industry are "environmental protection" and "high quality clean steel production". Therefore R\&D innovation is essential to strengthening international competitiveness of the steel product whole embracing these issues. The ultimate goals are to develop innovative iron-making processes using low grade ores and coals with less pollution materials and $\mathrm{CO}_{2}$ emission. EML seeks for (1) excellence in the world, (2) international global network development, and (3) collaboration with industry. Our mission is to develop innovative technologies in conventional and alternative ironmaking processes, that is, the development of environmentally conscious processes for steel production, waste materials and new resource development with minimum energy and $\mathrm{CO}_{2}$ emission.

Research areas the Lab currently focuses on include;

- Utilization of low grade iron ores in conventional sintering process for Blast Furnace operation

- Improvement of alternative ironmaking (FINEX) process

- Utilization of shale gas to new ironmaking process

- Research on carbonaceous materials for effective blast furnace operation
- Crystallization behavior of chemically modified BOF slag

\subsubsection{Clean Steel Lab (CSL)}

The Lab is aiming at contributing to our academic community and steel industry by carrying out research, education, and communication. Main research area of interest is chemical metallurgy, including chemical thermodynamics, kinetics, and solidification. Practical application area includes pyro-metallurgical process, in particular for steelmaking and continuous casting processes.

Research areas the Lab currently focuses on include,

- Hot metal pretreatment, primary steelmaking

- Steelmaking and refining

- Casting and solidification

- Fluid control

- Recycling of scrap

- Thermodynamics of steel, slag, inclusions, etc. appearing in steelmaking/casting process

- Reaction kinetics modeling to find efficient process route

- Physico-chemcial properties relevant to high temperature process (surface and interfacial tension, etc.)

\subsubsection{Control and Automation Lab (CAL)}

The Lab concentrates its efforts on developing effective treatment method of information and automatic control algorithm for steel making process. Software and systems engineering projects in the context of the CAL aim at improving automation systems and involve several target steel processes such as Hot rolling mill, Down coiler, Looper, Hydraulic and Motor system.

Research areas the Lab currently focuses on include,

- Development of Hardware-in the looper simulator

- Improvement of control algorithms

- Analyzing the effect of control algorithm

- Computer Aided Engineering tool based modelling with CAD

- Development of off-line simulator for continuous endless mill(CEM) process

- Development of off-line simulator for thick plate production process

- Fundamental study of stability in dynamic system.

\subsection{Materials Development Center}

The main activity of the Materials Development Center is understanding the physical metallurgy of various kinds of steels and finally developing new alloys like high strength high ductility automotive steels, oriented or non-oriented electrical steels, high Mn cryogenic steels, ultra-lightweight high-Al steels and high-nitrogen or lean duplex stainless steels.

The Center is run with four research labs:

- Material Design Lab (MDL) led by Prof. Bruno C. De Cooman

- Microstructure Control Lab (MCL) led by Prof. Nack Joon Kim

- Special Steel Lab (SSL) led by Prof. Sung-Joon Kim

- Alternative Technology Lab (ATL) led by Prof. Yang Mo Koo 
A brief description on research emphasis of each of the labs is given below:

\subsubsection{Material Design Lab (MDL)}

The focus of the Lab is physical materials - science and technology of steel products. It plays a research leadership role in the areas of advanced automotive steels, galvanized products, and steel grades related to power transportation and generation. It also has considerable expertise in the areas of steel products technologies, processing and process simulation with a special emphasis on hot rolling, cold rolling, continuous annealing and galvanizing. In addition, materials testing, physical properties determination, and steel micro-characterization using advanced techniques are also active research domains of the Lab. By emphasizing technical innovation for steel products, the Lab aims to set the agenda for future steel product development.

Research areas the Lab currently focuses on include,

- Advanced high strength steels for automotive applications

- Dual phase steels

- Transformation-induced plasticity steels

- Twinning induced plasticity steels

- Martensitic steels.

- Steel design concepts, processing issues and application-specific materials performance testing.

\subsubsection{Microstructure Control Lab (MCL)}

During the last decade considerable efforts have been made in structural materials research for various applications, particularly in transportation systems. Although the impetus for this comes from the various needs depending on the type of transportation systems, one common goal is to develop transportation system with improved performance. This can be achieved by using advanced materials with low density, high strength, high toughness, etc.

Research in the Microstructure Control Lab concerns the microstructural design of advanced materials including various types of steels and $\mathrm{Mg}$ alloys. The Microstructure Control Lab is unique in that it covers the R\&D on the non-ferrous alloys such as $\mathrm{Mg}$ alloys. Being a pioneer of the development of twin-roll casting process for $\mathrm{Mg}$ alloys, the Lab developed several $\mathrm{Mg}$ alloys, which are currently being used in several automobiles. Large emphasis is put on electron microscopy to understand the phase transformation behavior.

Current research projects include the followings:

- High Al containing light-weight steels

- High Mn steels for low temperature applications

- Ultra-high strength steels for aerospace applications

- Wrought Mg alloys formable at room temperature

- Solidification behavior of undercooled melts

\subsubsection{Special Steel Lab (SSL)}

Special Steels Lab deals with alloy design, processing technology, and characterization of corrosion resistant stainless steels, heat resistant high temperature steels, die steels, and various kinds of specialty steels. As the global concerns on the reduction of energy consumption, efficient usage of energy, and new findings and drilling of oil resources are growing, the demands for the specialty steels are rapidly rising. The biggest problem of specialty steels is that they usually contain very expensive elements. There are plenty of rooms for developing specialty steels with high performance with low price, and thus the Lab explores possibilities through a number of feasible routes.

Research areas the Lab currently focuses on include,

- Design and characterization of high performance stainless steels

- Design and failure analysis of high temperature steels

- Microstructural control and design of multiphase high strength automotive steels

- Investigation of process controlling mechanism

\subsubsection{Alternative Technology Lab (ATL)}

Alternative Technology Lab deals with long-term research in the areas of strategical importance. The Lab develops expertise especially in characterization of aimed ferrous materials using x-ray.

The Lab currently works on several functional materials including electrical applications and in-depth looking into recrystallization of particular ferrous alloys.

\subsection{Application \& Solution Center}

The Application \& Solution Center thrives to create economic and academic values by developing new steel applications and steel customer solutions originating from world-class academic research on product manufacturing, reliability and durability.

The Center will develop and establish promising advanced technology concepts for new steels and steel solution based on the synergistic application of state-of-the-art multiphysics and multi-scale modeling.

Major Research Areas of the Center include

- Computational physical metallurgy and microstructure analysis

- Design of nano-structured high strength steel products

- CAE-based forming technology for AHSS automotive parts

- Design of hot press forming processes for boron steel

- High-Mn steel wire resistant to hydrogen embrittlement, fatigue and fracture

- Smart coating technology for functional steel sheets

The Center is run with four research labs:

- Computational Metallurgy Lab (CML) led by Prof. Dong Woo Suh

- Materials Mechanics Lab (MML) led by Prof. Frederic Barlat

- Material Reliability Lab (MRL) led by Prof. Chong Soo Lee

- Surface Engineering Lab (SEL) led by Prof. Kyoo Young Kim

\subsubsection{Computational Metallurgy Lab (CML)}

The catch phrase of the Computational Metallurgy Lab is "We develop and exploit knowledge to create novel alloys of iron." The Lab develops new steels through employing computational methodology and experimental validation.

Research areas the Lab currently focuses on include, 
- Next generation higher-performance steels

- Phase transformations

- Theory of transformations

- Mathematical models

\subsubsection{Materials Mechanics Lab (MML)}

The Materials Mechanics Lab contributes to the development of innovative forming processes and products. The Lab focuses its research on advanced high strength steels (AHSS), stainless steels and other materials of interest.

In sheet forming, critical challenges for AHSS are the wrinkling tendency and springback, which both affect geometrical accuracy, lower achievable stretching strains and reduced drawing depths. Moreover, many products such as fuel cell separators made of stainless steel require tighter dimensional tolerances. Therefore, it is necessary to develop new numerical and experimental tools in order to successfully design innovative forming operations and products.

Although the fine-tuning of a product manufacturing is empirical, modeling is an efficient tool to guide and optimize design. Forming simulations are conducted using commercial finite element codes. One of the main inputs to the simulations is the so-called constitutive description, the mathematical representation of the material behavior. The goal of this numerical approach is to design new process and steel products in a short time by taking advantage of simulation technologies combined with new accurate and efficient constitutive descriptions. The challenge of this research is to develop accurate constitutive models for plastic deformation tailored to new steel generations, yet simple enough to allow time efficient numerical simulations at the scale of real products. Another challenge is to develop advanced mechanical testing, characterization and analysis in order to identify the constitutive parameters.

The general research focus is on,

- Advanced material characterization and forming processes

- Meso- and macro-scale constitutive modeling of plasticity

- Numerical simulations of forming processes

Research areas the Lab currently focuses on include,

- Reduction of springback during forming of AHSS automotive components

- Formability and ridging in thin ferritic stainless steel sheets

- Material models for multi-phase steels

\subsubsection{Material Reliability Lab (MRL)}

The Material Reliability Lab is focusing on research activities in the areas of fatigue and plasticity of various metallic alloys. The Lab challenges to elucidate the high temperature deformation mechanisms of various metallic alloys, and to clarify the microstructural influence on the fatigue resistance and formability of materials.

In the area of fatigue, the microstructural and environmental factors influencing fatigue properties (high cycle fatigue, low cycle fatigue and fatigue crack propagation) are investigated by using $\mathrm{Ti}, \mathrm{Al}$ and ferrous alloys. Recently, life prediction models for HCF and LCF have been extensively studied and confirmed by experimental verification. In the area of plasticity, research efforts have been devoted to understand the mechanism of high temperature deformation and to develop the intelligent forging processes of $\mathrm{Ti}$, $\mathrm{Al}$, and Fe alloys via computer simulation.

Research areas the Lab currently focuses on include,

- Fatigue properties of advanced structural materials

- Development of high-strength and ductile steels

- Hydrogen delayed fracture of high-strength steel

- Plastic working of high-performance nonferrous metal

- Modeling of the microstructure and mechanical properties

- Biomaterials for medical implants

\subsubsection{Surface Engineering Lab (SEL)}

The Surface Engineering Laboratory (SEL) studies the corrosion and protective coating technology for steel products through education of the students with scientific basics and applied research. SEL focuses on development of corrosion resistant steels for key strategic application required by future product design as well as on development of environmental- friendly smart coating technology. The high Mn steels are an attractive candidate material for oil/gas industry of ultra-deep extracting because of their high strength and high resistance to hydrogen permeability. Development of corrosion resistant high Mn steels is one of the key issues. Advancement of organic paint technology opens up new coating technology to develop self-healing smart paint using functional nano-coating technology and to develop environment-friendly coatings with application of photosensitive film technology.

Current research topics of SEL include:

- Development of corrosion resistant high strength Mn steels

- Intergranular corrosion study of low $\mathrm{Cr}$ ferritic stainless steel

- High temperature oxidation study of ferritic stainless for SOFC

- Development of self-healing paint for steel product

- New generation of automotive steel free of $\mathrm{Zn}$ coating

\section{An Example of Recent Achievement on Light- Weight Steel Development}

Recently a group of researchers in the Microstructure Control Lab of GIFT has developed a new alloy-design route to lightweight steel, demonstrating that the combination of specific strength and ductility accessible to steel is far greater than previously thought. Their work has been published in the journal "Nature" under the title of "Brittle intermetallic compound makes ultra-strong low-density steel with large ductility." "2) A brief summary of their work follows:

This work has made a novel approach to resolve the detrimental effect of the FeAl-type brittle but hard intermetallic compound (B2), the formation of which is unavoidable when it is attempted to develop high-aluminum low-density steels. The approach successfully made by this work was to induce B2 particles to precipitate in nanometer size in the face-centered cubic matrix of high-aluminum lowdensity steel. This was made possible by adding nickel as 
an alloying element which provided the catalytic effect for B2 particle precipitation as desired during heat treatment of cold-rolled sheet steel. In this way FeAl-type intermetallic compound (B2) could be effectively used as a strengthening second phase by controlling morphology and dispersion, otherwise it would be exceedingly harmful on mechanical properties like ductility. This new alloy shows large ductility and phenomenally high strain hardening capability even at ultrahigh yield strength levels of over $1 \mathrm{GPa}$. The proposed finding provides a new alloy-design route to lightweight steels, demonstrating that the combination of specific strength and ductility accessible to steels is greater than previously thought, and increasing the density-compensated tensile damage tolerance of structural metal for terrestrial applications. Furthermore, the attractive combination of physical and mechanical properties in the low-density steel described here is obtainable by simple thermal treatments which are compatible with existing commercial processes of the steel industry. The tuning of the distribution and morphology of brittle intermetallic compounds in steel matrix may be useful in many other steel applications.

\section{Concluding Remarks}

The Graduate Institute of Ferrous Technology (GIFT) under the umbrella of Pohang University of Science and Technology (POSTECH) in Korea was established in 2005 to carry heavy responsibility of educating young people who will serve the steel-based industries of the future and producing novel, innovative and breakthrough technologies which enable iron and steel to continue to contribute to the sustainable development of the society. Following its predecessor of the Graduate School of Iron and Steel Technology (GSIST) which served for 10 years to reeducate field engineers in the steel industry at the master's level, GIFT has been working to nurture elite scientists and technologists in ferrous technology at masters and PhD levels for the last 10 years. For the last 20 years, GIFT, including GSIST as well, conferred the master's degree to 466 graduates and the PhD degree to 96 graduates. It also carried out a number of research projects, many of which provided a driving force for advancement of ferrous technology in different areas. GIFT keeps well in mind that it is its promise to the society to play the key role for the ever-lasting future of iron and steel.

\section{Acknowledgements}

Advice and support of all academic and general staff members of GIFT are highly acknowledged. Information and data on GIFT are generously provided by Prof. C. S. Lee, Dean of GIFT.

\section{REFERENCES}

1) Hae-Geon Lee: Ironmaking Steelmaking, 33 (2006), No. 3, 193.

2) S.-H. Kim, H. Kim and N. J. Kim: Nature, 518 (2015), 77. 